This item was submitted to Loughborough's Research Repository by the author.

Items in Figshare are protected by copyright, with all rights reserved, unless otherwise indicated.

\title{
Media framing of trolling and online abuse: silencing strategies, symbolic violence and victim blaming
}

PLEASE CITE THE PUBLISHED VERSION

http://dx.doi.org/10.1080/14680777.2017.1316755

\section{PUBLISHER}

(c) Taylor \& Francis

\section{VERSION}

AM (Accepted Manuscript)

\section{PUBLISHER STATEMENT}

This work is made available according to the conditions of the Creative Commons Attribution-NonCommercialNoDerivatives 4.0 International (CC BY-NC-ND 4.0) licence. Full details of this licence are available at: https://creativecommons.org/licenses/by-nc-nd/4.0/

\section{LICENCE}

CC BY-NC-ND 4.0

\section{REPOSITORY RECORD}

Lumsden, Karen, and Heather M. Morgan. 2019. "Media Framing of Trolling and Online Abuse: Silencing Strategies, Symbolic Violence and Victim Blaming”. figshare. https://hdl.handle.net/2134/24489. 
This is a pre-print version of the article published in Feminist Media Studies Vol.17, No.6 (December 2017).

Media Framing of Trolling and Online Abuse: Silencing Strategies, Symbolic Violence and Victim Blaming

\title{
Dr Karen Lumsden and Dr Heather M. Morgan
}

\section{Corresponding author details}

Dr Karen Lumsden, Senior Lecturer in Sociology, Department of Social Sciences, Loughborough University, Loughborough, LE11 3TU, United Kingdom. Email K.Lumsden@1boro.ac.uk Tel: +44 (0) 1509228372

\section{Co-author details}

Dr Heather Morgan, Research Fellow, Health Sciences Unit, University of Aberdeen, $3^{\text {rd }}$ Floor, Health Sciences Building, Foresterhill, Aberdeen, AB25 2ZD, United Kingdom. Email h.morgan@abdn.ac.uk Tel: +44 (0) 1224438192

\begin{abstract}
This article draws on British newspaper reports in order to demonstrate that trolling, and the media's subsequent framing of trolling, involves "silencing strategies". It is important to examine how trolling is discussed within the media to understand how it might frame public opinion, debate and action, and implicitly victim blame. The article presents findings on: the forms of (online) abuse and behaviours related to trolling in media reports, including rape threats, death threats and body shaming. It also explores the media portrayal of victims of trolling, and the advice given concerning how to respond to trolls. To comply with the message to women, which is propagated in media and popular discourses: "do not feed the
\end{abstract}


This is a pre-print version of the article published in Feminist Media Studies Vol.17, No.6 (December 2017).

troll", means that "symbolic violence" is exercised with the complicity of the victim(s) of trolling, which has broader implications.

\section{Keywords}

Framing, online abuse, rape, social media, trolling, victims

\section{Introduction}

This article focuses on the framing of trolling in British newspaper reports. Trolling is a form of gendered and "symbolic violence" (Pierre Bourdieu \& Loic J. D. Wacquant 1992) as it is performed in relation to women and other minority groups on social media platforms such as Twitter, Instagram and Facebook (Lumsden and Morgan forthcoming). Media reports, public debate and academic research concerning the 'dark side' of the web have focused on the rise of online abuse including trolling (Whitney Phillips 2015), hate crime, Islamophobia (Imran Awan 2016), cyber-bulling, revenge porn, stalking, and sexting. However, the media's framing of trolling and online abuse has been largely overlooked in academic studies. Jane (2014a: 532) argues that "extravagant invective, the sexualized threats of violence, and the recreational nastiness that have come to constitute a dominant tenor of Internet discourse", should be a priority for academic analysis instead of being treated as a moral panic. She also points out that not reprinting examples of online abuse can undermine how academics understand the nature of trolling, as it is then deemed "unspeakable". It is important to examine how trolling is discussed within the media to understand how it might frame public opinion, debate and action, and implicitly victim blame via "silencing strategies".

The tactics employed by trolls, including rape threats and death threats, can be viewed as examples of "silencing strategies". "Silencing strategies" attempt to remove the individual 
This is a pre-print version of the article published in Feminist Media Studies Vol.17, No.6 (December 2017).

from participation in (online) public space (such as on social media sites), or dissuade them from engaging in further public debate (by responding to or challenging an offensive "tweet" on Twitter or photograph on Instagram). The media portrayal and framing of trolling can be said to reinforce these "silencing strategies". For example, as we will show, the advice given to those who are victims of online abuse - "do not feed the troll" (for fear of provoking the troll further) - is a "silencing strategy", for in doing so the victim is unable to challenge or resist abusive (i.e. sexist, racist or misogynist) language and attitudes. Underlying the trolling of visible and audible women is the deeply entrenched misogynistic idea of silencing women (Sarah Beresford 2015). "Silencing strategies" are reflected in the ways in which the media report on trolling, including: the reconstruction of the trolling event (such as rape threats, death threats, and body shaming); the representation of the (female) victim; and the advice given to victims on how they should respond to online abuse.

To address our collective knowledge gap around media framing of trolling and online abuse, this article proceeds as follows. First, it reviews literature on trolling and gendered violence in online spaces. It then discusses media framing, the legitimization and normalization of violence and rape in media reports, and victim blaming. After outlining the relevance of Bourdieu's (1990) concept of "symbolic violence" for understanding online abuse and the media framing of trolling, the discussion focuses on the methods utilised in an analysis of British press reports of trolling. Results are then presented which centre on the forms of (online) abuse and behaviours related to trolling in media reports, including rape threats, death threats and body shaming. The discussion also explores the media portrayal of victims of trolling, and the advice given to the public on how to respond to trolls (i.e. "do not feed the troll"). It is argued that trolling places victims in a powerless position and limits freedom of expression. The media framing reinforces this notion that women are (or should be) powerless, 
This is a pre-print version of the article published in Feminist Media Studies Vol.17, No.6 (December 2017).

devaluing and stigmatising them, and victim blames. The advice to women which is propagated in media and popular discourses: "do not feed the troll", is a form of "symbolic violence" promoting victim complicity with online abuse.

\section{Review of the literature: trolling and gendered online abuse}

Studies of trolling have developed from concern with early internet users' trolling of online forms and bulletin boards (also referred to as "flaming"), to the recent use of the term trolling to refer to abuse on social media sites, comments pages and blogs. Trolling differs from flaming "in that the goal of flame bait is to incite any and all readers, whereas the goal of a stereotypical troll is to draw in particularly naive or vulnerable readers" (Susan C. Herring et al. 2002: 372). Claire Hardaker (2010) claims that trolling consists of four interrelated characteristics: aggression, deception, disruption and success. Situational factors, including anonymity, have also been found to contribute to trolling interactions and behaviours (Myiah J. Hutchens et al. 2015). Analyses of online abuse also highlight the tension between "libertarian and communitarian values, in that harassment often arises in spaces known for their freedom, lack of censure, and experimental nature" (Herring et al. 2002: 374).

Scholars have also studied trolling as a subcultural practice. In her work on Use Net News Groups, Judith S. Donarth (1999) focuses on the conditions which give rise to identity deception in online communities. Here, trolling is described as: "where you set your fishing lines in the water and then slowly go back and forth dragging the bait and hoping for a bite" (1999: 45). In a study of self-identifying "subcultural trolls" in the USA, Whitney Phillips (2015: 2) highlights trolling's relationship to the wider media cultural landscape. Trolls engage in "media fuckery", which is the "ability to turn the media against itself". This is accomplished by amplifying or inventing a sensational news story (Phillips 2015: 4-5). 
This is a pre-print version of the article published in Feminist Media Studies Vol.17, No.6 (December 2017).

Trolling behaviour is also normalized by those doing the trolling - as play or as the lingua franca of particular platforms such as 4chan and Reddit (Phillips 2015).

"Gendertrolling" is viewed as distinct from subcultural trolling, which attempts to disrupt or hijack online interactions (Karla Mantilla 2015). Gendertrolls have a motivation that is "more vicious, virulent, aggressive, threatening, pervasive, and enduring... gendertrolls take their cause seriously, so they are ... able to rally others who share in their convictions... [and] are devoted to targeting the designated person" (Mantilla 2015: 11). New forms of media can therefore exacerbate issues surrounding sexual violence through the creation of digital spaces in which the perpetration and legitimization of sexual violence takes on new qualities. Online harassment is a means of excluding women's voices from digital spaces, although it is argued that women have never been equal online (Jessica Megarry 2014). When a woman's behaviour is perceived to be deviant from the norms of submissive femininity, the online abuse received is also particularly reliant on the positioning women as sex objects (Megarry 2014).

Rape and death threats are the most prominent forms of gendertrolling, targeted at women online. Rape threats which form part of the lingua franca of trolls are part of the wider reemergence of "rape culture" within popular discourse in the past five years. "Rape culture" is: "a socio-cultural context in which an aggressive male sexuality is eroticized and seen as a 'healthy', 'normal', and 'desired' part of sexual relations" (Jessalyn M. Keller, Kaitlynn D. Mendes \& Jessica Ringrose 2015: 5). It is: “A complex set of beliefs that encourage male sexual aggression and supports violence against women ... condones physical and emotional terrorism against women and presents it as the norm ..." (Emilie Buchwald, Pamela R. Fletcher \& Martha Roth 2005: xi). This discourse has become normalized to the extent that 
This is a pre-print version of the article published in Feminist Media Studies Vol.17, No.6 (December 2017).

rape threats are now the modus operandi for individuals who want to critique female commentators (Jane 2014a). Online abuse both redeploys existing manifestations of rape culture and intensifies them due to the speed at which images and written communications can be shared online (Shaheen Shariff \& Ashley DeMartini 2015). Sophie Sills et al. (2016) interviewed young people about their exposure and responses to rape culture on social media. Their participants were viewed as living within a "matrix of sexism" in which sexism, misogyny, and rape culture are a normalized part of everyday life. "Victim-shaming" and “slut-shaming" were viewed as commonplace (Sills et al. 2016: 7). Trolling is situated within the wider social and cultural context of the rise of "lad culture" where sexist and misogynistic language and treatment of women is lauded and admired by peers (openly and flagrantly displayed online in sites such as the 'Lad Bible', and racist and sexist trolling on social media sites). Trolling must be viewed within this context, as a means of silencing women's voices online and their participation in virtual public space(s), resulting in the heteronormative masculinization of virtual space.

Previous studies have highlighted a pattern to women's responses to abuse occurring in the offline context. James E. Gruber (1989) highlights four strategies of responding to abuse which include: avoidance, diffusion, negotiation, and confrontation. Research on sexual harassment in the workplace indicates that women's responses tend to involve "nonassertiveness" towards their harassers (James E. Gruber \& Michael D. Smith 2010). It is therefore also important to focus on how victims respond to their harassers online, how the media portray victims' responses and what public advice is given on how to respond, in order to further explore how this is linked to gendered stereotypes of women as non-confrontational and silent. 
This is a pre-print version of the article published in Feminist Media Studies Vol.17, No.6 (December 2017).

\section{Media framing}

The term "trolling" is now widely utilised by the media to describe the posting of offensive messages by an individual or group in addition to the more proactive, deliberate and organised hate campaigns engaged in by groups of individuals, in a pre-meditated manner. Trolling has "become a catch-all term for any number of negatively marked online behaviours" (Hardaker 2010: 224). However, the media framing of trolling and online abuse has been largely overlooked in academic studies. Media framing refers to the ways in which news stories are organized by "patterns of selection, emphasis, interpretation, and exclusion" (Caragee \& Roefs cited in Nancy Worthington 2008: 4; see also Stephen D. Reese 2001; Todd Gitlin 2003; Robert Entman 2007). It is a means of identifying the hidden meanings in news stories, including which facts are included or left out (Carolyn M. Byerly 1999). As Robert Entman (1993: 52) argues, journalists "frame" by "select[ing] some aspects of a perceived reality and mak[ing] them more salient in a communicating text." Frames can define and identify problems, make moral judgements and suggest solutions, while also serving to maintain power and the status quo (Barbara Barnett 2016; Entman 1993). Framing can shape public understanding and influence public policy (Barnett 2016). Frames also have symbolic power and use "myths, narratives and metaphors that resonate within the culture" (Hertog \& McLeod cited in Anne Johnston et al. 2014: 422).

Through their framing of women's issues, the media provide ideological support for hegemonic power structures and reproduce dominant culture (Marian Meyers 1994; Zeynep Alat 2006). Therefore, we are interested in the extent to which it can be said to support and/or reproduce online discourses of trolling/abuse. Previous studies have demonstrated how violence against women is legitimized through the ways in which media reports focus on the positions of victims in terms of family, domesticity and gender norms (Deborah Jermyn 
This is a pre-print version of the article published in Feminist Media Studies Vol.17, No.6 (December 2017).

2001). Media framing of rape has the "potential to shape the societal perceptions of rape" (Stephanie Bonnes 2013: 210). In relation to media reports of sexual violence and rape in Turkey, Alat (2006: 301) notes how they adopted a "victim blaming" stance with women "accused of lying about consensual sex and calling it rape for revenge". Michael Salter (2013) notes the ways in which victims of sexual violence and their supporters are developing online strategies for assessing and acting upon allegations of sexual violence. Despite these strategies, "the criminal justice system and 'old media' are underpinned by homo-social cultures and relations that can marginalise and disrupt the truth claims of ... women" (2013: 238). Furthermore, media framing of women's issues presents and reinforces traditional images of femininity where women are objectified and portrayed as passive and submissive (Laura Ashley \& Beth Olson 1998; Diana B. Carlin \& Kelly L. Winfrey 2009; Burnett 2016). It is therefore crucial we analyze how the old media frame victims' stories of online abuse as a women's issue.

\section{Bourdieu and symbolic violence}

Pierre Bourdieu (1998) and researchers close to him were interested in the social and political consequences of media process and were highly critical of its "symbolic power" (Nick Couldry 2003). The media, as a sphere of cultural production, can be analysed as:

a single field, or a collection of fields, (each) with a distinctive pattern of prestige and status and its own values. Indeed ... the media's intermediate position between the cultural and economic poles of the wider cultural field gives them a particular interest as a field. (Couldry 2003: 657) 
This is a pre-print version of the article published in Feminist Media Studies Vol.17, No.6 (December 2017).

The "symbolic power" of the media can be understood as a power "of a self-fulfilling prophecy and is dependent on our unwitting complicity and legitimation" (Nick Crossley 2001: 318). Some concentrations of "symbolic power" are so strong that: "they dominate the whole social landscape; as a result, they seem so natural that they are misrecognized, and their underlying arbitrariness becomes difficult to see. In this way, symbolic power moves to ... 'a power of constructing social reality" (Couldry 2003: 664). Therefore "symbolic power" in the media field (re)produces and legitimizes social categories and beliefs.

In Bourdieu's work, the concepts of "symbolic power" and "symbolic violence" are used interchangeably. Crossley (2001: 319) argues that if there is any difference in Bourdieu's usage it is that "symbolic violence" is often used to refer to the way in which social agents "come to accept the categories and social systems which, in turn, are imposed on them - and whose power they unwittingly sanction." However, he proposes that "symbolic power" is more appropriate here, and that we should instead understand "symbolic violence" as referring to instances in which "particular groups are systematically denied the degree of recognition enjoyed by others ... instances where they are devalued or stigmatized" (Crossley 2001: 319, our emphasis). "Symbolic violence" helps to capture the "felt and/or lived suffering of those devalued, stigmatized or otherwise denied a basic level of recognition by their wider society" (ibid).

To analyse the media framing of trolling, we draw on this utilisation of "symbolic violence". For the sake of clarity, we utilise this term (instead of "symbolic power"), throughout the article, to refer to the ways that "symbolic violence" is enacted upon women (and minority groups) in media reports of trolling, resulting in their devaluing and/or stigmatization. Bourdieu's work has relevance for feminism and analysis of gender relations. By drawing on 
This is a pre-print version of the article published in Feminist Media Studies Vol.17, No.6 (December 2017).

Bourdieu's work, we can view "symbolic violence" as a process of social reproduction (Angela McRobbie 2004). Social inequalities (classed, racialized, and gendered) are "perpetuated as power relations directed towards [online] bodies and the 'dispositions of individuals" (McRobbie 2004: 103). It is violence which is "exercised upon a social agent with his or her complicity" (Bourdieu \& Wacquant 1992: 167). Examples of the exercise of "symbolic violence" include gender relations in which both men and women agree that women are weaker, less intelligent and unreliable. For Bourdieu, gender relations are the paradigm case of the operation of "symbolic violence" (McRobbie 2004). We argue that "symbolic violence" towards women in the digital realm encourages complicity, while reproducing and reinforcing established gender roles. This leaks into offline spaces including the ways in which the "old media" frame online abuse and victim blame.

\section{Method}

Qualitative document analysis (David L. Altheide 1987; 1996) was applied to 175 newspaper reports of trolling from British national newspapers including broadsheets and tabloids. In the UK, the distinction between the tabloid and broadsheet press is based on the size of the press, with broadsheets typically larger than tabloids, and in terms of the readership, with broadsheets aimed at "the educated and professional middle classes and tabloids concentrating on the working and lower middles classes" (Katy Day et al. 2004: 168). We recognised the need to make evident examples of trolling in the British press, and the construction of the (female) victim of trolling (Jane 2014a). Hence this article aims to open doors for future studies of media framing of online abuse. We wanted to explore how the media were utilising, framing and constructing trolling as a form of online abuse. Our initial research questions were: 1) what forms of (online) abuse and behaviours are related to trolling in media reports? 3) how do the media portray the victims of trolling? 4) how do the 
This is a pre-print version of the article published in Feminist Media Studies Vol.17, No.6 (December 2017).

media portray the offender (troll)? 5) how do the media frame the victim's response to trolling? 6) what advice do the media communicate to the public on how to respond to trolling? 7) how do the media rationalise trolling on the part of the offender? 8) how do they report on the role of external agencies including the authorities and social media corporations? 9) how do the media report on the relationship between online abuse in the virtual world and its relationship to the offline world?

\section{Sampling}

A search for newspaper reports was conducted using LexisNexis with the keyword "trolling" and involved "saturation sampling". Data saturation is normatively taken to mean that data should continue to be collected until nothing new is generated and there are no more emergent patterns in the data (Michelle O'Reilly \& Nicola Parker 2012). The search included the headline of articles and covered UK national newspapers over a five-year period from 4 November $2010^{1}$ to 8 October 2015 . From 248 results, 175 articles were included for analysis after we removed duplicate articles and those which utilised trolling in non-social media contexts. We also removed reader opinion letters. We narrowed the search to the term trolling and did not use other synonymous terms as we were particularly interested in how the phenomenon of trolling and victims' experiences of trolling, were framed, constructed, and reported in the mainstream press. An initial search for "troll" in the headline using the above dates recovered over 3000 results which needed to be reduced for analysis, hence the decision to focus on "trolling". We recognise this as a limitation and therefore future studies would benefit by exploring the media framing of online abuse using synonymous terms. The majority of reports we analysed were classified under the "news" category, while a minority featured in the categories of "people", "celebrity news", "features", "technology", "front page", "politics", "science", "life and art" and "comment and debate". The majority of articles 
This is a pre-print version of the article published in Feminist Media Studies Vol.17, No.6 (December 2017).

focused on trolling in Britain (with the exception of a handful which focused on the trolling of celebrities in Australia and the USA).

Analysis

As noted above, we used qualitative analysis "to document and understand the communication of meaning, as well as to verify theoretical relationships" (Altheide 1987: 68). This is a distinctive form of analysis because of the reflexive and interactive nature of the investigator, concepts, data collection and analysis. With this interpretive approach, the idea is to allow for reflexivity, "while being systematic and analytic, but not rigid" (Altheide 1987: 68). We were interested in the substantive content of narratives and "discourses-in-practice" (Jaber F. Gubrium \& James A. Holstein 2000). We allowed our initial research questions, categories and themes to guide the analysis, but others were also expected to emerge throughout the study (Altheide 1987). We utilised a matrix to analyse the media framing of trolling which included an inventory (i.e. publication, date, length, etc.) and content variables (i.e. actors involved, topics, events, setting, context, timeframe, etc.). We began by reviewing the articles in relation to our research questions, utilising the matrix for the inventory and content. We then viewed them to explore recurrent themes which emerged naturally from the data utilising axial and open coding (Altheide 1996). In this article, we are concerned with findings on: the forms of (online) abuse and behaviours related to trolling in media reports. We will also touch upon: the media portrayal of victims of trolling; and the advice which the media communicate to the public on how to respond to trolling.

\section{Results: the framing of trolling in the British media}

We focus on how trolling events were framed by the British media, and how they silenced and committed "symbolic violence" against the victims. Reports of trolling referred to 
This is a pre-print version of the article published in Feminist Media Studies Vol.17, No.6 (December 2017).

multiple forms of misogyny and sexism including violence, rape, death threats, and body shaming (for instance reference to appearance, body, weight and nudity). Table 1 highlights the number of reports which included these themes, and provides a breakdown of the percentages in tabloid and broadsheet newspapers.

\begin{tabular}{|c|c|c|c|}
\hline Theme & Tabloid \% & Broadsheet \% & $\begin{array}{l}\text { Total } \\
\text { number }\end{array}$ \\
\hline Violence & 71 & 29 & 45 \\
\hline Rape & 64 & 36 & 44 \\
\hline Death & 66 & 34 & 70 \\
\hline $\begin{array}{l}\text { Body shaming (i.e. appearance, body, weight, } \\
\text { nudity) }\end{array}$ & 68 & 32 & 28 \\
\hline
\end{tabular}

Table 1: Percentage of trolling reports in British national newspapers which featured the themes: 'violence', 'death', 'rape', and 'body shaming'. $n=175$

There was a pattern in which reports of trolling featured more frequently in the tabloid press, reflecting a general focus on stories featuring celebrities and sports personalities. The broadsheet papers more frequently cited the experiences of politicians, business people, and high profile cases of public victims of trolling. Reports of trolling in tabloid and broadsheet papers more frequently referenced death threats, followed by rape threats. Reports would often focus on trolling which included a combination of these themes. 
This is a pre-print version of the article published in Feminist Media Studies Vol.17, No.6 (December 2017).

\section{Rape and death threats}

Reports of trolling in both tabloid and broadsheet British media most frequently referred to violent acts, particularly rape and death threats, experienced by female victims in the public eye, such as politicians, television presenters, and musicians. These examples demonstrate the increasingly prevalent "rape culture" which incorporates aspects of popular misogyny, and entails anti-female violent expression via the threats of rape and death (or bodily harm) directed at women online. Expressions of aggressive male sexuality are eroticized in the online sphere (Keller, Mendes \& Ringrose 2015) and in the press. These reports focused on the posting of visual images online. For instance, a report referred to the Australian DJ Alison Wonderland who:

received the abuse alongside a photo of herself sitting on the ground with her legs apart ... Instagram trolls said they wanted to "roofie" and "rape" her ... Thousands of people had "liked" the photograph ... before the first of the offenders commented: "Can we rape her or something please," tagging the other with the Instagram handle ... The second responded by looping in another follower, seemingly alleging him to say: "I would roofie her". 2

The media framing of the abuse as something which the DJ "received" portrays her as a willing and submissive participant in that she was the one who opted to post the photo, thus "opening herself up" to public scrutiny. This is indicative of implicit victim blaming in that the response is framed as a direct result of her actions. The description of the photo - "sitting on the ground with her legs apart" also suggests a typical portrayal of a submissive female, with her "legs spread" and who was thus "asking for it" - asking to be trolled. This demonstrates how the media framing of "rape threat trolling" focuses on the norm of 
This is a pre-print version of the article published in Feminist Media Studies Vol.17, No.6 (December 2017).

submissive femininity and is reliant on the positioning women as sex objects (Megarry 2014).

Media reports of trolling normalize "rape culture" in the online sphere.

In reports of "rape threat trolling", gender has been intersected with race, for example in the case of the blogger and YouTuber Kat Blaque, who campaigns for equality and was subjected to a "torrent of racist and sexist insults" by a user called Kenneth:

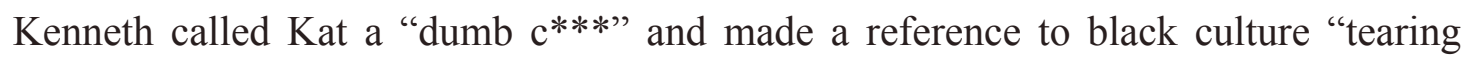
things down". In one post, he makes a public rape threat, telling Kat: "I'd throw you on the bed and ravage you and you'd $\mathrm{f}^{* * * * * *}$ love it”. In another ... after claiming that he didn't make a rape accusation, he writes: "It's alright. You'll get yours. Remember I'm a conservative, I like my guns."

The media are reinforcing the myth in relation to rape that women will "enjoy it" ("you'd $\mathrm{f}^{* * * * * *}$ love it"). In response to the abuse she received, Kat posted a message to followers on her Facebook page. The media framing of her response - that the threat itself did not bother her, it was the people defending him that did - also points to the normalization of rape culture and rape threats in the mainstream media framing of trolling:

Kenneth threatening to rape and kill me didnt bother me. Thats part of my daily existence. Having people rush to defend him however? That fucks with me so much. Im glad i never reported my rape. I couldn't handle this 6 years ago. I can hardly handle it now. Being told to take this shit lightly really messes with me. 'What did you expect' are words that ring in my head. The exact words i heard when i told my friends $\mathrm{i}$ was raped. This is why women remain silent. And the people defending 
This is a pre-print version of the article published in Feminist Media Studies Vol.17, No.6 (December 2017).

kenneth will never get that. So many people suffer in silence and i wrote about Kenneth because its one of the rare, small victories that we can have and so many people were part of it. $[\mathrm{sic}]^{4}$

The report likens the advice to "stay silent" regarding sexual violence against women in the offline context, to the advice received by women who receive online rape threats. The rhetoric employed individualizes the women, and also focuses on her body as an object and target for violence (Kirsti K. Cole 2015).

Businesswoman Jo Bertram, boss of Uber car service UK, was also sent offensive tweets:

Jo Bertram ... has been bombarded with offensive tweets, including messages about rape, her appearance and the suggestion that she should be "run over" ... Under his Twitter name "Arnold Circus", Kaczorowski joined a conversation thread in which other cab drivers were discussing Uber's "safety record for women passengers". The previous tweeter had mentioned Bertram and asked: "Wonder what she must feel every time a woman is sexually assaulted in an Uber car?" Kaczorowski wrote: "Perhaps she gets a little tingle between her legs. U never know she may like it." In another post he called Bertram a "ropey old bint". 5

This excerpt highlights the sexist and misogynist abuse directed at a woman who is viewed as "incompetent" by men in terms of her occupation and gender. Women who entered spaces typically deemed to be "man's domain" were viewed as "doubly deviant": deviant for being online and deviant for daring to enter into a male-dominated workplace. As Sandy Welsh (1999: 170) argues "sexual harassment is ... about letting women know they are not welcome 
This is a pre-print version of the article published in Feminist Media Studies Vol.17, No.6 (December 2017).

in certain workplaces and that they are not respected members of the work group." Sexual harassment is an attempt by men to maintain their dominance (Kimberly Fairchild \& Laurie Rudman 2008). Often, it was women's lives in the offline context which the media rationalised as a motive for the sending of death threats. This was the case for the British television presenter Sue Perkins who received abuse after rumours (later confirmed as untrue) spread that she would be taking over from Jeremy Clarkson as a presenter on the BBC's Top Gear programme:

Sue revealed to fans on her social media account earlier this week Top Gear fans had been "wishing me dead" after it was rumoured she was being lined up to take a leading role in the motoring show. She wrote: "[since] the utterly fabricated story about me \& Top Gear, my timeline has been full of blokes wishing me dead ... This morning someone suggested they'd like to see me burn to death.",6

The stereotype of women as "witches" is used alongside rape and/or death threats (the latter including threats of "burning to death"), as evident in the below trolling of the Labour Member of Parliament (MP) Stella Creasy and the feminist campaigner Caroline CriadoPerez, who campaigned for a woman to appear on a bank note (with the Bank of England later choosing to print Jane Austen). The troll in this instance was jailed for 18 weeks and had:

retweeted a threatening message ... which read: "You better watch your back, I'm going to rape you're $\mathrm{a}^{* *} \mathrm{e}$ at $8 \mathrm{pm}$ and put the video all over [the internet]" ... In his next message he posted: "Best way to rape a witch, try and drown her first then just when she's gagging for air that's when you enter" ... Later that evening he wrote: "If you can't threaten to rape a celebrity, what is the point in having them?" ... He called 
This is a pre-print version of the article published in Feminist Media Studies Vol.17, No.6 (December 2017).

the Labour MP an "evil witch" and wrote: "What's the odds of [Criado] and Creasy snuggling and cuddling under a duvet checking their tweets and cackling like witches (rape me says Caroline).",

As also noted above in relation to the blogger, Kat Blaque, in media reports of trolling there was a tendency to draw on examples of rape threats on social media which highlighted how the victim should/would "enjoy" the sexual act. Traces of the myth that rape is a sexual act which women can enjoy are easily found in sensational and titillating coverage of rape crimes and this extends to threats of rape online (Alat 2006).

\section{Body shaming}

Body shaming was a prominent form of trolling which the media focused on, linked to the posting of images on Instagram, and with victims receiving negative comments linked to their appearance, in addition to rape and death threats. The presence of the "male gaze" (Laura Mulvey 1975[1992]) is evident via both mainstream media and digital media scrutiny of the female body. Megarry (2014: 50) notes that offensive comments aimed at women online often “displayed a preoccupation with physical appearance and suggested that a woman's worth and value lies in her sexual appeal to men." In the example below, the musician Nicki Minaj was reported to have been "mocked for her appearance" on Instagram. However, the report silences the voice of the victim and engages in victim blaming, as it likens her response to the trolls as a form of "public shaming", making implicit the underlying advice that she should have ignored or "not fed the trolls". Her strategy of re-posting pictures of those trolling her involved the reversal of the "gaze" to give "fans a taste of their own medicine": 
This is a pre-print version of the article published in Feminist Media Studies Vol.17, No.6 (December 2017).

Minaj has never been one to take verbal abuse lying down, and after a string of cruel comments about her appearance on her Instagram page the rapper decided to give fans a taste of their own medicine. She had been Instagramming pictures from her brother Jelani's wedding, which she allegedly paid for in full, when someone made comments about her hair... Minaj retaliated by going onto the Instagram accounts of people who were rude to her and posting their selfies on her account to see how they liked being scrutinised... But following complaints she was "bullying" people, Minaj took to Twitter to justify her actions, and hit out at the double standards she gets when she tries standing up for herself:

Lol can I just be on my own page minding my business in peace? Lmao. When I post a pic of a person dissin me I'm a bully? Lol this world... - NICKI MINAJ (@NICKMINAJ) August, 23 2015.8

The assertive response of Minaj in the form of reposting her abusers' own "selfies" is framed as a form of "bullying". This highlights the societal expectations around how women should publicly respond to (online) abuse (i.e. adopt a submissive position). Minaj's strategy goes against the grain of the atypical "non-assertive" responses that previous studies of responses to sexual abuse have highlighted (Gruber 1989). Jane (2014b) also argues in relation to "ebile" that it is women who speak publicly about being targeted online who then receive more abuse. Women are deemed to be "inferior" and to function for the provision of "sexual gratification for men"" however they are then denigrated for this "self-same characterization" (Jane 2014b: 566). 
This is a pre-print version of the article published in Feminist Media Studies Vol.17, No.6 (December 2017).

Media reports also focused on the historian and academic Mary Beard, who described the abuse she received after she appeared on BBC's Question Time debate programme:

They discussed whether I needed rogering, and how I was an "ignorant $* * * *$ " and a disgrace to Cambridge University and woman-kind. There were more "c" words and "f" words and "p" words than you could imagine ... There were also comments about what an embarrassment she must be to her husband and two grown-up children, pictures of horribly hairy legs (supposedly hers), endless comments about her pubic hair (and more), and how she was "a vile, spiteful excuse for a woman who eats too much cabbage and has cheese straws for teeth."9

The attacks on Mary Beard can be viewed as responses to her failure to adhere to those normative standards of feminine beauty and appearance which are expected from women who enter the world of media and public commentary. This online harassment involves the utilisation of stereotypical ideas of femininity in a derogatory manner as noted by Megarry (2014). Myths in media reports abounded with regards to victimisation of women because of their "careless behaviour" (Alat 2006) or that entering into the public spotlight brought with it a number of responsibilities and expectations, including accepting that this entailed the public's right to critique television personalities and that women who make public media appearances must abide by the norms of feminine beauty.

\section{Discussion and conclusions}

This article drew on a qualitative content analysis of British media reports of trolling to demonstrate the ways in which the media frame online abuse and how they implicitly victim blame. It is argued that media reports of trolling adopt the use of "silencing strategies" which 
This is a pre-print version of the article published in Feminist Media Studies Vol.17, No.6 (December 2017).

can be viewed as a form of "symbolic violence" (Bourdieu 1990). Results were presented which centred on the forms of (online) harassment and behaviours related to trolling in media reports, including rape threats, death threats, and body shaming linked to norms of femininity. The discussion also explored the media framing of victims of trolling, and the advice given to the public on how to respond to trolls (i.e. "do not feed the troll”). Although extensive work in media studies over the last fifteen years has helped to bridge the conceptual divide between the real/material and virtual/immaterial, images of this divide still pervade old media press coverage.

Media portrayals of trolling and rape threats have the potential to shape societal perceptions of rape (Bonnes 2013). Victim blaming was common in media reports with women accused of exaggerating or falsifying the impact of online rape threats (Alat 2006). The myth that women can/will enjoy rape or were "asking for it", was also reflected in media framing of victims of online abuse. The old media are still "underpinned by homo-social cultures and relations that can marginalise and disrupt the truth claims of ... women" (Salter 2013: 238). Therefore, there is a need for more social scientific research into media portrayals of online abuse, experiences of online abuse, and how social media is reshaping, but also replicating, traditional practices and discourses of violence, gender and communication.

Media frames of trolling reinforce the normalization of online violence against women as an extension of or proxy for gendered violence (Rena Bivens 2015). As Jenny Kitzinger (2004: 14) argues media coverage can "decontextualize abuse, encourage racism, promote stereotypes of women (as virgins or whores), blame victims, and excuse assailants." Media reports framed victims of online abuse as powerless and submissive in line with typical norms of femininity noted in previous studies of the media framing of women's issues (Ashley \& 
This is a pre-print version of the article published in Feminist Media Studies Vol.17, No.6 (December 2017).

Olson 1998; Burnett 2016). Women were viewed as sex objects and also portrayed as passive victims of online abuse.

Social media sites, through their design and the anonymity they can afford users, rest power in the hands of the troll, while the victim is encouraged in media reports and public discourses on trolling to be complicit in the ways in which they respond to online abuse via the use of "silencing strategies". However, to adhere to the message: "do not feed the troll", means that "symbolic violence" is exercised with the complicity of the victim(s) of trolling (McRobbie 2004). The message to women using online spaces which is reflected in media reports can be summed up as similar to the age-old sexist adage: "if you can't stand the heat, get out of the kitchen." Victims are advised to remember that no harm is intended (i.e. it is only "banter") and also not to provoke the troll further. These strategies do not address the issue of abuse, misogyny and sexism, but require women to be complicit in the exercise of "symbolic violence". Bourdieu's work is therefore useful for analysing how "social arrangement along gender lines takes shape within ... media $\ldots$ by means of habitus adjustment to ensure conformity with the contemporary requirements" of the social media field/s (McRobbie 2004: 108). Both the old media and social media play a key role in (re)-forming and reinforcing social classifications and stereotypes.

It is also problematic that trolling has become a catch-all term used by the old media to also refer to less sinister forms of debate or disagreement between various individuals/groups. This trivialises and disguises the extent and impact of online abuse as a form of "symbolic violence" towards women and other minority groups. Therefore, further work is required in feminist media studies which acknowledges the relationship between online abuse and the (gendered) frames and discourses of the traditional media. 
This is a pre-print version of the article published in Feminist Media Studies Vol.17, No.6 (December 2017).

\section{References}

Alat, Zeynep. 2006. "News Coverage of Violence Against Women.” Feminist Media Studies 6 (3): $295-314$.

Altheide, L. David. 1987. “Ethnographic Content Analysis.” Qualitative Sociology 10 (1): 6577.

Altheide, L. David. 1996. Qualitative Media Analysis, London: Sage.

Ashley, Laura, and Beth Olson. 1998. “Constructing Reality: Print Media's Framing of the Women's Movement, 1966 to 1986." Journalism and Mass Communication Quarterly 75 (2): 263-277.

Awan, Imran, ed. 2016. Islamophobia in Cyberspace, London: Routledge.

Barnett, Barbara. 2016. "Dividing Women: The Framing of Trafficking for Sexual Exploitation in Magazines.” Feminist Media Studies 16 (2): 205-222.

Beresford, Sarah. 2015. "From Scolds to Trolls: Social and Legal Responses to Visible and Audible Women - A Conference Blob.” Lancaster University Law School. Accessed February 20, 2017. http://www.lancaster.ac.uk/law/blogs/staff/from-scolds-to-trolls-socialand-legal-responses-to-visible-and-audible-women/

Bivens, Rena. 2015. "Under the Hood: The Software in Your Feminist Approach.” Feminist Media Studies 15 (4): 714-717.

Bonnes, Stephanie. 2013. "Gender and Racial Stereotyping in Rape Coverage." Feminist Media Studies 13 (2): 208-227.

Bourdieu, Pierre. 1990. Language and Symbolic Power, Cambridge: Polity Press.

Bourdieu, Pierre. 1998. On Television and Journalism, London: Pluto Press.

Bourdieu, Pierre, and Loic J. D. Wacquant. 1992. An Invitation to Reflexive Sociology, Cambridge: Polity Press. 
This is a pre-print version of the article published in Feminist Media Studies Vol.17, No.6 (December 2017).

Buchwald, Emilie, Pamela R. Fletcher, and Martha Roth. eds. 2005. Transforming a Rape Culture, Minneapolis, MN: Milkweed Editions.

Byerly, Carolyn M. 1999. "News, Feminism, and the Dialectics of Gender Relations." In: Mediated Women: Representations in Popular Culture, ed. Marian Meyers, Hampton Press, Cresskill, NJ, pp. 383-403.

Carlin, Diana B., and Kelly L. Winfrey. 2009. "Have You Come a Long Way, Baby? Hillary Clinton, Sarah Palin, and Sexism in 2008 Campaign Coverage.” Communication Studies 60 (4): $326-343$.

Cole, K. Kirsti. 2005. “'It's Like She's Eager to be Verbally Abused': Twitter, Trolls and (En)gendering Disciplinary Rhetoric.” Feminist Media Studies 15 (2): 356-358.

Couldry, Nick. 2003. "Media Meta-Capital: Extending the Range of Bourdieu's Field Theory." Theory and Society 32: 653-677.

Crossley, Nick. 2001. Key Concepts in Critical Social Theory, London: Sage.

Day, Katy, Brendan Gough, and Majella McFadden. 2004. "Warning! Alcohol Can Seriously Damage Your Feminine Health!” Feminist Media Studies 4 (2): 165-183.

Donarth, S. Judith. 1999. "Identity and Deception in the Virtual Community". In: Marc A. Smith and Peter Kollock, eds, Communities in Cyberspace, London: Routledge, pp. 29-59.

Entman, Robert. 1993. “Framing: Toward Clarification of a Fractured Paradigm.” Journal of Communication 43 (4): 51-58.

Entman, Robert. 2007. "Framing Bias: Media in the Distribution of Power." Journal of Communication 57 (1): 163-173.

Fairchild, Kimberly, and Laurie A. Rudman. 2008. "Everyday Stranger Harassment and Women's Objectification.” Social Justice Research 21 (3): 338-357. 
This is a pre-print version of the article published in Feminist Media Studies Vol.17, No.6 (December 2017).

Fogg, Ally. 2010. "Do Not Jail the Troll." The Guardian. September 8, 2016. https://www.theguardian.com/commentisfree/libertycentral/2010/nov/04/trolls-are-offensive$\underline{\text { but-not-criminals }}$

Gitlin, Todd. 2003. The Whole World is Watching: Mass Media in the Making and Unmaking of the New Left. Berkeley, University of California Press.

Gruber, E. James. 1989. "How Women Handle Sexual Harassment: A Literature Review." Sociology and Social Research 74: 3-9.

Gruber, E. James, and Michael D. Smith. 1995. "Women's Responses to Sexual Harassment." Basic and Applied Social Psychology 17 (4): 543-562.

Gubrium, F. Jaber, and James A. Holstein. 2000. “Analyzing Interpretive Practice.” In: Norman K. Denzin and Yvonna S. Lincoln, eds, Handbook of Qualitative Research, 2nd edn, London: Sage, pp. 487-508.

Hardaker, Claire. 2010. "Trolling in Asynchronous Computer Mediated Communication: From User Discussions to Academic Definitions.” Journal of Politeness Research 6: 215-242. Herring, C. Susan, Kirk Job-Sluder, Rebecca Scheckler, and Sasha Barab. 2002. "Searching For Safety Online: Managing 'Trolling' in a Feminist Forum.” The Information Society 18: 371-384.

Hutchens J. Myiah, Vincent J. Cicchirillo, and Jay D. Hmielowski. 2015. "How Could You Think That?!?!: Understanding Intentions to Engage in Political Flaming." New Media \& Society 17 (8): 1201-1219.

Jane, A. Emma. 2014a. “'You're a Ugly, Whorish, Slut'.” Feminist Media Studies 14 (4): 531-546.

Jane, A. Emma. 2014b. “'Back to the Kitchen, Cunt': Speaking the Unspeakable About Online Misogyny." Continuum 28 (4): 558-570. 
This is a pre-print version of the article published in Feminist Media Studies Vol.17, No.6 (December 2017).

Jermyn, Deborah. 2001. "Death of the Girl Next Door: Celebrity, Femininity, and Tragedy in the Murder of Jill Dando." Feminist Media Studies 1 (3): 343-359.

Johnston, Anne, Barbara Friedman, and Autumn Shafer. 2014. "Framing the Problem of Sex Trafficking." Feminist Media Studies 14 (3): 419-436.Keller M. Jessalyn, Kaitlynn D. Mendes, and Jessica Ringrose. 2015. “Speaking 'Unthinkable Things': Documenting Digital Feminist Responses to Rape Culture.” Journal of Gender Studies. Pre-print version. Accessed March 14, 2016. https://lra.le.ac.uk/handle/2381/33121

Kitzinger, Jenny. 2004. "Media Coverage of Sexual Violence Against Women and Children." In: Karen Ross and Carolyn M. Byerly, eds, Women and Media: International Perspectives, Oxford: Blackwell Publishing, pp. 13-28.

Lumsden, Karen, and Heather M. Morgan. Forthcoming. "Cyber-Trolling as Symbolic Violence: Deconstructing Gendered Abuse Online.” In Gender and Violence, Nancy Lombard, ed. Aldershot: Ashgate.

Mantilla, Karla. 2015. Gendertrolling, Westport, Connecticut: Praeger.

McRobbie, Angela. 2004. 'Notes on 'What Not to Wear' and Post-Feminist Symbolic Violence." Sociological Review 52 (2): 97-109.

Megarry, Jessica. 2014. “Online Incivility or Sexual Harassment? Conceptualising Women’s Experiences in the Digital Age.” Women's Studies International Forum 47: 46-55.

Meyers, Marian. 1994. “News of Battering.” Journal of Communication 44 (2): 47-63.

Mulvey, Laura. 1975[1992]. "Visual Pleasure and Narrative Cinema.” In: The Sexual Subject, New York: Routledge, pp. 22-34.

O’Reilly, Michelle, and Nicola Parker. 2012. “'Unsatisfactory Saturation': A Critical Exploration of the Notion of Saturated Sample Sizes in Qualitative Research." Qualitative Research 13 (2): 190-197.

Phillips, Whitney. 2015. This is Why We Can't Have Nice Things, Cambridge, MA: MIT 
This is a pre-print version of the article published in Feminist Media Studies Vol.17, No.6 (December 2017).

Press.

Reese, Stephen D. 2001. "Prologue - Framing Public Life: A Bridging Model for Media Research.” In: Framing Public Life: Perspectives on Media and Our Understanding of the Social World, edited by Stephen D. Reese, Oscar H. Gandy, and August E. Grant, Mahwah, NJ: Lawrence Erlbaum Associates, pp. 7-31.

Salter, Michael. 2013. "Justice and Revenge in Online Counter-Publics: Emerging Responses to Sexual Violence in the Age of Social Media." Crime. Media, Culture 9 (3): 225-242.

Shariff, Shaheen, and Ashley DeMartini. 2015. "Defining the Legal Lines: eGirls and Intimate Images." In: Jane Bayley and Valerie Steeves, eds, eGirls, eCitizens, Ottawa: University of Ottawa Press, pp. 281-306.

Sills Sophie, Chelsea Pickens, Karishma Beach, Lloyd Jones, Octavia Calder-Dawe, Paulette Benton-Greig, and Nicola Gavey. 2016. "Rape Culture and Social Media: Young Critics and a Feminist Counterpublic." Feminist Media Studies iFirst. DOI: $10.1080 / 14680777.2015 .1137962$

TG Daily. 2010. “Facebook Takes (Small) Step Against Tribute Page Trolls.” March 30, 2010. Accessed September 8, 2016. http:/www.tgdaily.com/software-features/49166-facebook$\underline{\text { takes-small-step-against-tribute-page-trolls }}$

Trolling: The Today Show Explores the Dark Side of the Internet. March 31, 2010. Accessed September 8, 2016.

Welsh, Sandy. 1999. “Gender and Sexual Harassment.” Annual Review of Sociology 25 (1): 169-190.

Worthington, Nancy. 2008. "Progress and Persistent Problems.” Feminist Media Studies 8 (1): $1-16$. 
This is a pre-print version of the article published in Feminist Media Studies Vol.17, No.6 (December 2017).

\section{Author biographies}

Karen Lumsden is Senior Lecturer in Sociology at Loughborough University. She is author of Boy Racer Culture (Routledge, 2013), co-editor of Reflexivity in Criminological Research (Palgrave Macmillan, 2014) and has published in a range of journals including Sociology, Qualitative Research, Sociological Research Online, Policing \& Society and Mobilities. She is on the Editorial Board of Sociological Research Online. Research interests include policing, crime, youth culture and social media, with contributions to methodological debates on ethnography and reflexivity.

Heather joined the Health Services Research Unit, University of Aberdeen in 2012. She is a Research Fellow with a multidisciplinary social science background and she contributes to the Delivery of Care programme. Heather specialises in research where technologies meet surveillance/monitoring, compliance/deviance and gender. Heather is currently exploring uses of health self-monitoring technologies (apps, wearables, etc.). Her previous work has looked at self-management of long-term health conditions, interventions for healthy behaviours in pregnancy, and gender in police CCTV.

\section{Notes}

${ }^{1}$ Although the concept of the troll was coined in the late 1980 s in relation to trolling subcultures on Use Net forums (Donarth 1999), it was not until 2010 that political controversy and media attention turned to trolling on social media. In Australia and the USA attention centred on the trolling of adolescents who had committed suicide, and murder victims (i.e. the Today Show in 2010 reported on the trolling reaction to the death of three adolescent girls, while in Australia political outrage centred on the trolling of Facebook tribute pages set up for two murdered adolescents (TG Daily 2010)). In the UK, media and 
This is a pre-print version of the article published in Feminist Media Studies Vol.17, No.6 (December 2017).

political concern increased following a host of high profile trolling incidents related to Facebook tribute pages (i.e. Colm Cross was sentenced to 18 weeks in prison for targeting tribute pages including one set up for the celebrity Jade Goody, and another set up for deceased children (Ally Fogg 2010)).

${ }^{2}$ Soldani, B. 2015. "“You should always stand up for yourself.' Australian DJ Alison Wonderland speaks out after Intragram trolls said they wanted to 'roofie' and 'rape' her." Mail Online. October 8.

${ }^{3}$ Bolton, D. 2015. "Blogger Kat Blaque tracked down her troll and got him fired." Independent. September 30.

${ }^{4}$ Bolton, D. 2015. "Blogger Kat Blaque tracked down her troll and got him fired;." Independent. September 30, 2015.

${ }^{5}$ Henry, R. 2015. "Uber boss victim of cabbie trolls.” The Sunday Times. July 5, 2015.

${ }^{6}$ Thistlethwaite, F. 2015. "James May tells Top Gear fans trolling Sue Perkins to 'kill themselves' on Twitter." Express. April 17.

${ }^{7}$ Williams, A. 2014. "Twitter troll who threatened to rape Labour MP Stella Creasy in row over Jane Austen appearing on $£ 10$ notes is jailed for 18 weeks.” MailOnline. September 29.

${ }^{8}$ Mandle, C. 2015. "Nicki Minaj tells trolls to stay off her Instagram after publicly shaming people for mocking her appearance.” Independent. August 25.

${ }^{9}$ Fryer, J. 2013 “How I turned the tables on my trolls.” Mail Online. January 26. 